\title{
ONLINE WRITTEN EXAMS AT THE UNIVERSITY OF MILAN DURING COVID-19 CRISIS
}

\author{
Goffredo Haus, Yuri Pasquinelli, Daniela Scaccia and Nello Scarabottolo \\ Università degli Studi di Milano, Italy
}

\begin{abstract}
The paper deals with the problem of carrying on online written exams in the University of Milan, suddenly closed due to the Covid-19 emergency. Main goal of the paper is to present and compare the different scenarios envisioned, depending on the number of students to be monitored in parallel to avoid cheating. After illustrating the solutions identified at the beginning of the pandemic, the paper concentrates on what happened since May 2020 up the end of April 2021, when these solutions have been adopted by the University. In particular, the paper shows how the different envisaged scenarios have been perceived and applied by the teachers. An analysis of grades given to students before and during pandemic is also included.
\end{abstract}

\section{KEYWORDS}

Written Exams, Online Student Monitoring, Proctoring

\section{INTRODUCTION}

The lockdown imposed by the Covid-19 pandemic around the end of February 2020 forced the University of Milan (as well as all other Italian Universities) to transfer suddenly online all the teaching activities normally carried on with students physically present in classrooms in a traditional university.

Due to these urgent requirements, the implementation of online lectures has been left to the personal initiative of teachers, without the possibility of significant methodological guidelines, as the ones discussed, e.g., in Troussas et al. (2020), Xiao et al. (2020), Troussas et al. (2021). The support offered by the university personnel mainly consisted in a set of instructions published on the web portal helping teachers in registering audio and video lectures, in connecting with students through web conference platforms, in publishing didactical materials on the proprietary LMS (Learning Management Systems). 
ONLINE WRITTEN EXAMS AT THE UNIVERSITY OF MILAN DURING COVID-19 CRISIS

A similar approach has been followed to allow the thesis discussion of graduating students: the web conference platforms used for lectures have also been adopted to connect these students from home with the teachers evaluating their final exam.

On the contrary, particular attention has been paid to the management of exams evaluating the knowledge and the competences acquired by students at the end of each single course present in their study curricula, as already presented in Haus et al. (2020) and Haus et al. (2021). Among the various references in literature regarding online exams, it is worth mentioning Truszkowski (2019), Ardid et al. (2015) and Weiner \& Hurtz (2017). In the first two, some comparisons between proctored and non-proctored tests are made, clearly showing that in the absence of some form of proctoring the final grades are higher, due to usage of unauthorized support and cheating. In the third one, a comparison between online and onsite proctored exams shows, on the contrary, no significant differences in final grades, allowing to state that the level of student behavior control can be satisfactory both online and onsite.

To better understand the context, it is worth noticing that the University of Milan is constituted by height faculties:

- Agricultural and Food Sciences,

- Humanities,

- Law,

- Medicine,

- Pharmacy,

- Political, Economic and Social Sciences,

- Science and Technology,

- Veterinary Medicine

and 2 schools:

- Exercise and Sport Sciences,

- Language Mediation and Intercultural Communication.

They offer 67 bachelor degrees (3 years, 180 ECTS - European Credit Transfer System credits) 64 master degrees ( 2 years after bachelor, 120 ECTS credits) and 9 single-cycle master degrees (5 or 6 years, 300 or 360 ECTS credits). 2179 staff professors and almost 2000 contract professors, supported by 1960 support people (technical and administrative staff units) teach every year more than 3000 courses.

To proctor exams online, the first suggestion coming from the University governance to all teachers has been to convert them in oral form, and to interact with students through the same web conference platforms used for teaching, to be able to evaluate and to grade them. However, this approach presents several limitations, in particular:

- the impossibility in an oral exam to ask students to solve problems requiring (even a short) autonomous work, perhaps to be written by hand on a piece of paper;

- the troubles in finding a set of equally difficult questions to pose to several students (thus the troubles in making a fair evaluation);

- the excessive time required for courses followed by hundreds of students.

For the above reasons, the authors of this paper:

- the Deputy Rector for Digital Innovation, ICT Services, Strategic and Special Projects;

- the Director of the ICT Division;

- the Director of CTU: the Teaching and Learning Innovation and Multimedia Technology Center of the University;

- the Rector Delegate to ICT infrastructures coordination;

have been charged with the task of studying possible ways to conduct online written exams, 
allowing teachers to avoid the limitations of oral exams while still guaranteeing a reasonable level of reliability in their evaluations. To this purpose, main aspects to be taken into account were:

- the possibility of submitting to students open answer tests as well as closed answer quizzes;

- the possibility of asking students to submit their work (partially or totally) written on paper, for example when mathematical formulas or graphical elements are required;

- the possibility for students to use some applications (e.g., compilers, statistical software, etc.) during their exam;

- the possibility of examining groups of students ranging from a few units to a few hundreds;

- the possibility of adopting technological solutions enforcing teacher's control over students behavior (i.e., avoiding students to copy answers, to surf the web and to interact among each other during the exam).

The following section summarizes the impact of exams in our University, in terms of numbers of students and distribution over the year. Section 3 discusses different approaches to monitor student behavior during their exams, on the basis of the number of participating students. Section 4 presents three different scenarios identified by the authors and proposed around the end of April 2020 to the teachers of the university, letting them to adopt the most suitable one(s) for their needs. In section 5, the usage of these solutions in the academic year 2020-21 (i.e., from May 2020 to end of April 2021) is considered in terms of numbers of exams, numbers of examined students, etc. Section 6 gives some insights into the grades given to students before and during pandemic. Section 7 draws some concluding remarks and possible future developments of this aspect of online learning.

\section{ANALYSIS OF EXAM SESSIONS}

Before describing the different scenarios identified for the management of written exams, it is worth knowing that in our University:

- each course must propose to students at least six different exam sessions every academic year;

- every student can freely decide when to apply for the exam after the end of the course lectures, but, in case of failure or unsatisfying result, she/he can reapply for the same exam in a following session, without any penalty;

- there is even no penalty for students that after application do not show up at the exam session: they are simply considered absent and they can reapply whenever they want.

This means that:

- each teacher has to plan for at least six exam sessions every year, with a number of participating students known only a few days before each session, i.e., after the end of the student application period for each exam session;

- the real number of examined students in each session depends on how many students do not show up even after application.

To evaluate the impact of written exams data related to the last complete "normal" academic year 2018-19 have been taken into account. The results are shown in Tables 1 and 2. 
ONLINE WRITTEN EXAMS AT THE UNIVERSITY OF MILAN DURING COVID-19 CRISIS

Table 1. Written exam sessions in academic year 2018-19

\begin{tabular}{lccccc}
\hline Month & $\begin{array}{c}\text { Exam } \\
\text { sessions }\end{array}$ & $\begin{array}{c}\text { Applying } \\
\text { students }\end{array}$ & $\begin{array}{c}\text { Graded } \\
\text { students }\end{array}$ & $\begin{array}{c}\text { Average applying } \\
\text { students per session }\end{array}$ & $\begin{array}{c}\text { Max applying } \\
\text { students per session }\end{array}$ \\
\hline May & 1.102 & 25.677 & 9.068 & 23,3 & 302 \\
June & 2.477 & 51.301 & 29.891 & 20,7 & 428 \\
July & 3.197 & 49.074 & 26.697 & 15,4 & 206 \\
September & 3.043 & 39.083 & 19.735 & 12,8 & 223 \\
October & 497 & 5.533 & 2.663 & 11,1 & 245 \\
November & 896 & 19.780 & 6.025 & 22,1 & 545 \\
December & 827 & 23.464 & 13.966 & 28,4 & 401 \\
January & 2.116 & 45.617 & 23.452 & 21,6 & 309 \\
February & 2.868 & 54.806 & 26.759 & 19,1 & 353 \\
March & 471 & 8.998 & 5.763 & 19,1 & 275 \\
April & 838 & 18.255 & 10.349 & 21,8 & 214 \\
\hline Total & $\mathbf{1 8 . 3 3 2}$ & $\mathbf{3 4 1 . 5 8 8}$ & $\mathbf{1 7 4 . 3 6 8}$ & $\mathbf{1 8 , 6}$ & $\mathbf{5 4 5}$ \\
\hline
\end{tabular}

Table 2. Distribution of students and sessions per faculties in academic year 2018-19

\begin{tabular}{|c|c|c|c|}
\hline Faculty/School & $\begin{array}{c}\text { Enrollments } \\
\text { in } 2018 / 19 \\
\end{array}$ & $\begin{array}{c}\text { Exam } \\
\text { sessions }\end{array}$ & $\begin{array}{c}\text { Examined } \\
\text { students }\end{array}$ \\
\hline Agricultural and Food Sciences & 3.431 & $1^{\circ} 613$ & $27 \cdot 462$ \\
\hline Exercise and Sport Sciences & $1 ‘ 398$ & 349 & $9 \cdot 518$ \\
\hline Humanities & $14 \cdot 878$ & $1^{\bullet} 037$ & $32 \cdot 633$ \\
\hline Language Mediation and Intercultural Communication & $4 \cdot 737$ & $1 \cdot 115$ & $32 \cdot 394$ \\
\hline Law & $6 \cdot 748$ & 397 & $10 \cdot 696$ \\
\hline Medicine & $7 \cdot 682$ & $5 \cdot 494$ & $62 \cdot 523$ \\
\hline Pharmacy & $3 \cdot 075$ & $1 \cdot 161$ & $24 \cdot 286$ \\
\hline Political, Economic and Social Sciences & $7 \cdot 708$ & $2 \cdot 614$ & $53 \cdot 776$ \\
\hline Science and Technology & $8 \cdot 450$ & $3 \cdot 823$ & $75 \cdot 325$ \\
\hline Veterinary Medicine & $1 \cdot 836$ & 729 & $12 \cdot 975$ \\
\hline Total & $59 \cdot 943$ & $18 \cdot 332$ & 341588 \\
\hline
\end{tabular}

Tables 1 and 2 allow to draw the following considerations:

- the very low number of graded students (about half the number of students applying to exam sessions) is only partially due to students applying but not showing up: there are several written exams - often with lot of students - not producing a final grade but just an intermediate result, e.g. to be integrated by an oral exam;

- the largest number of exam sessions are located at the end of the winter and summer semesters, during breaks between lecture times (i.e., June-September and JanuaryFebruary, with August being the traditional vacation month in our country);

- the average number of students applying for each exam session is reasonably limited, and equal to 18.6 considering the overall year, but:

- there are exam sessions characterized by huge numbers of applying students: over 200 and up to 540 for a couple of exams;

- the largest number of exam sessions is organized by the faculty of Medicine, far above the faculty of Science and Technology which has the largest number of examined students;

- Humanities, i.e., the faculty where the highest number of students are enrolled, usually adopts oral exams, thus the number of written sessions is quite limited. 
To propose to our colleagues suitable scenarios for conducting written exams online, we had then to consider such a wide variety of situations in terms of student numbers, always keeping in mind their uneven distribution over the year.

\section{MONITORING STUDENT BEHAVIOR DURING EXAMS}

A first discriminating aspect considered in defining the different scenarios has been the possibility for the teacher to monitor in real time the behavior of the whole set of examined students or of a limited number of student groups through some web conference platforms.

After some tests, we concluded that a reasonable number of students that can be monitored by a single person is in the range of $20 \div 30$, and that it was not worth to ask teachers to split students in more than 4 to 5 groups, to be monitored in parallel (with the help of some collaborators) or one after each other. Then, we decided to consider 100 students applying for the same exam date as the limit for exam sessions monitored under teacher's responsibility and exams sessions requiring external support.

Table 3 subdivides the number of sessions already given in Table 1 using this threshold to discriminate between sessions with less than 100 applying students and sessions with 100 or more applying students. As it can be seen, the percentage of large sessions is definitely limited, even if they must deal with a number of applying students corresponding to $20 \%$ of the total number of students registered to exams in academic year 2018-19.

Table 3. Exam sessions in 2018-19 having less or at least 100 applying students

\begin{tabular}{|c|c|c|c|c|c|}
\hline Month & $\begin{array}{c}\text { \# of } \\
\text { sessions }\end{array}$ & $\begin{array}{l}\text { Sessions with } \\
<100 \text { students }\end{array}$ & $\begin{array}{l}\text { Large sessions with } \\
\geq \mathbf{1 0 0} \text { students }\end{array}$ & $\begin{array}{c}\% \text { of large } \\
\text { sessions }\end{array}$ & $\begin{array}{c}\text { \# of students in } \\
\text { large sessions }\end{array}$ \\
\hline May & $1 \cdot 102$ & $1 \cdot 056$ & 46 & $4.17 \%$ & $7 \cdot 443$ \\
\hline June & $2 \cdot 477$ & $2 \cdot 413$ & 64 & $2.58 \%$ & $9 \cdot 865$ \\
\hline July & $3 \cdot 197$ & $3 \cdot 163$ & 34 & $1.06 \%$ & $4 \cdot 383$ \\
\hline September & $3 \cdot 043$ & $3^{\circ} 021$ & 22 & $0.72 \%$ & $2 \cdot 995$ \\
\hline October & 497 & 494 & 3 & $0.60 \%$ & 545 \\
\hline November & 896 & 856 & 40 & $4.46 \%$ & $7 \cdot 752$ \\
\hline December & 827 & 768 & 59 & $7.13 \%$ & $10^{\circ} 245$ \\
\hline January & $2 \cdot 116$ & $2^{\circ} 043$ & 73 & $3.45 \%$ & 11269 \\
\hline February & $2 \cdot 868$ & $2 \cdot 819$ & 49 & $1.71 \%$ & $7 \cdot 299$ \\
\hline March & 471 & 458 & 13 & $2.76 \%$ & $2 \cdot 166$ \\
\hline April & 838 & 804 & 34 & $4.06 \%$ & $5 \cdot 056$ \\
\hline Total & $18 \cdot 332$ & $17 \cdot 895$ & 437 & $2.38 \%$ & $69^{\circ} 018$ \\
\hline
\end{tabular}

\subsection{Direct Monitoring}

Monitoring of a group of 20-30 students by means of a web conference platform (e.g., Microsoft Teams, Zoom, etc.) has been proposed in the following way:

- the web conference is established between the computer of the teacher and the smartphone of each student, who is requested to install the app of the web conference adopted by the teacher;

- students are admitted to the web conference planned by the teacher one after each other;

- after admission to the web conference, the student has to show an identity document to the 
ONLINE WRITTEN EXAMS AT THE UNIVERSITY OF MILAN DURING COVID-19 CRISIS

teacher (to prove her/his right to participate to the exam;

- the teacher can ask the student to use her/his smartphone to show the room where she/he will take the exam, to demonstrate that no other people nor other support device (e.g., a second computer) is present;

- then, the student must position her/his smartphone - suitably powered to avoid battery exhaustion - as shown in Figure 1, in order to frame her/his work place (table and computer desktop).

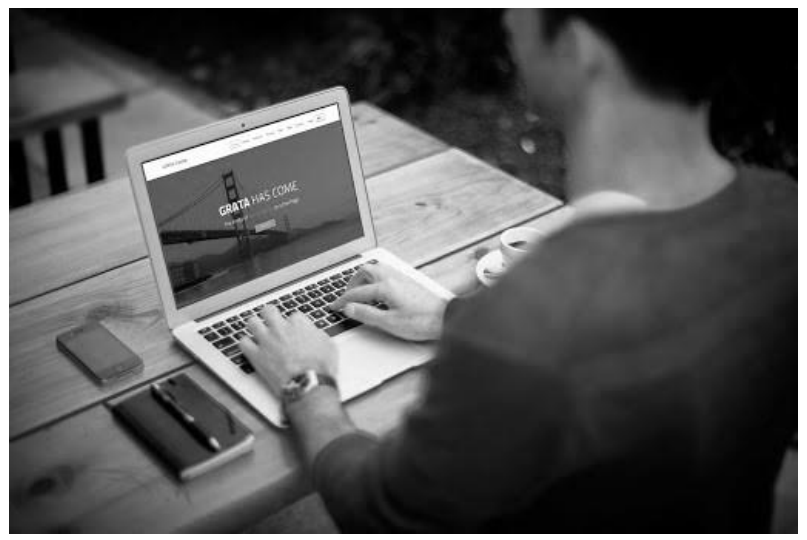

Figure 1. Student smartphone framing student work place

Student monitoring through her/his smartphone instead of through her/his computer proved to have several advantages:

- the teacher can control that no forbidden material (e.g., books, written notes, other smartphone, etc.) is used by the student during the exam;

- by zooming on each student window in the web conference, the teacher can look at the desktop and see if the student is operating correctly (i.e., using only the allowed applications);

- the audio of the student smartphone is always kept on, allowing to immediately identify unexpected noises, other people's voices, etc.;

- students have no idea about what is the web conference window examined in each moment by the teacher, who can randomly browse among them. This has a psychological effect on student behavior, since they must expect to be deeply controlled in any moment.

Of course, this monitoring relies from one side on the reliability of the connection between student smartphone and web conference platform, and on the other side on the ability of the teacher to properly handle the web conference.

As regards the first aspect, the student may have a low quality internet connection (maybe due to the area where her/his home is located), her/his smartphone may have heating troubles after too much time of video and audio connection, or she/he may have other problem resulting in unexpected end of her/his presence in the web conference. In these cases, it is up to the teacher to decide how to proceed: our suggestion is to let the student to try recovering the connection quickly; in case of failure, she/he must have a second chance in the following days, either as part of a successive student group, or as a single examined student, perhaps in oral form.

As regards the second aspect, we published a set of guidelines on the University web portal to help teachers to train themselves before undergoing their exams. Up to now the only critical 
situation happened for a teacher not realizing in time that a group of students in a larger set was not monitored at all, and he decided to cancel the exams of that group, obviously raising student complaints that left the University governance to force the teacher to re-admit them.

\subsection{Proctoring}

When 100 or more students applied for a single exam session, it is not worth asking the teacher to monitor many student groups, either in parallel (too many collaborators needed) or in sequence (too much time required).

We then started considering different proctoring proposals available on the market, i.e., systems offering different kinds of monitoring supports having these general characteristics:

- no control in real time by the teacher or other collaborators is required: the systems record the behavior of the student during the exam through the webcam of her/his computer, and/or a second device like a smartphone;

- after the end of the exam, all recordings are processed by suitable Artificial Intelligence algorithms, that mark in red any "suspect" behavior of the student (e.g., eyes or head movements, noises, appearance of other people, etc.);

- the marked tracks are then sent to the teacher together with all recordings, to allow her/him to analyze the suspect behaviors and decide accordingly how to manage them.

Among the various offerings, we concentrated on two options, namely: Respondus and Proctorio, described in (Respondus 2020) and (Proctorio 2020); after some initial tests, the second one was selected, mainly due to the more straightforward setup of the student computer and the reduced amount of frames stored during recording.

\section{SCENARIOS FOR CONDUCTING WRITTEN EXAMS}

Besides identifying the most suitable ways to monitor student behavior, we had to take into account the nature of the exam each teacher may decide to use; as already stated in the introduction, we had then to consider:

- the possibility of submitting to students open answer tests as well as closed answer quizzes;

- the possibility of asking students to submit their work written on paper;

- the possibility for students to use some applications (e.g., compilers, statistical software, etc.) during their exam.

The resulting scenarios identified and proposed to our University teachers are described in the following subsections.

\subsection{Open Answer Tests}

For limited numbers of students - i.e., groups that can be monitored by the teacher - a proposed scenario is based on the exam.net platform (Exam.net 2020) implemented by the Swedish company Teachiq AB and free to use outside Sweden during 2020. Main characteristics of this platform are:

- a very easy teacher interface, greatly facilitating creation and test of exams; 
ONLINE WRITTEN EXAMS AT THE UNIVERSITY OF MILAN DURING COVID-19 CRISIS

- real time monitoring of student work, since the teacher can browse among students and see what each of them already wrote;

- chat support, allowing the teacher to interact with every student without disturbing the overall group;

- download of student work as a pdf file for correction and grading;

- possibility for students to include pictures of hand written work, taken through their smartphone in a controlled way (QR code generated by the platform to allow each student to take and submit her/his pictures).

Moreover, since the visibility of the student desktop through her/his smartphone (as described in section 3.1) can be limited by environment lighting, non ideal smartphone positioning, etc., the scenario adopts the safer approach proposed by exam.net and based on the usage of SEB (Safe Exam Browser). As stated in (SEB 2020) SEB is a software that turns any computer temporarily into a secure workstation. It controls access to resources like system functions, other websites and applications and prevents unauthorized resources being used during an exam. SEB cannot be considered totally safe: some ways to bypass it are claimed to exist, though not so easy to implement (usage of virtual machines, access through a second computer, etc.). However, the appearance of the student desktop when SEB is running and the back monitoring through student smartphone facilitate the teacher work in identifying such bypasses.

For larger numbers of students, requiring proctoring, Proctorio has been integrated with the Moodle LMS already adopted by CTU, where several types of exam questions can be defined and submitted to students. The only unavailable option is the possibility for students to submit handwritten contributions, since the activities required to students (scan contributions and send them to the teacher) are not compatible with the AI monitoring approach of all proctoring systems.

\subsection{Closed Answer Quizzes}

The exam.net platform cannot be easily used for this kind of exams: it has no native support for quizzes and it does not integrate with an LMS like Moodle; it just gives the possibility to indicate some URLs accessible through SEB during the exam. However, there is no guarantee that from these URLs it is not possible to start surfing the web; moreover, we had several troubles in integrating exam.net with the Single Sign On feature of our University, used by students to authenticate themselves.

For the above reasons, closed answer quizzes for limited numbers of students (as well as any other types of exams that can be defined in Moodle) are implemented by directly integrating SEB with the Moodle LMS, without passing through exam.net.

For large numbers of students, quizzes are obviously handled through proctoring.

\subsection{Exams Requiring usage of External Applications}

A reliable control of the actual usage of computer programs like compilers, spreadsheets, statistical software, and so forth, made by students during the exam cannot be easily ensured, especially for groups of students directly monitored by the teacher. In fact, even when the student desktop can be clearly seen by the teacher, it is almost impossible to ensure that no other unadmitted programs or websites are accessed during the exam. 
The only possible approach, allowed e.g. by Proctorio, is the adoption of proctoring for student monitoring, but this would result in a far larger number of exam sessions requiring such a solution. In fact, since even for small student groups it would become necessary to set up a proctoring session, this would lead to extra costs but above all to unaffordable workload for the technicians managing them.

For these reasons, teachers have been requested to convert this kind of exams into an oral format.

\section{WRITTEN EXAMS DURING ACADEMIC YEAR 2020-21}

Table 4 shows the results of applying the scenarios described above and after the first complete academic year (May 2020 through April 2021).

As it can be seen, the scenario based on the exam.net platform (i.e., open answer questions or quizzes with few questions, for groups of students directly monitored by the teacher) shows a huge number of sessions and the largest number of examined students. It is clear that such a way of examining students has been greatly appreciated by our colleagues: in fact, it allows teachers not familiar with Moodle to submit written exams also to very small groups of students, exploiting all the facilities and friendliness of that platform.

Moodle - initially used by only a few teachers - shows some significant figures, even because some tests for evaluating basic student competences in using a PC have been moved to Moodle during 2020-21. In some cases, teachers decided to avoid the complexities related to the integration between Moodle and SEB.

As already said, proctoring has been limited to sessions with large numbers of students, $(99.8$ during the academic year) perfectly in line with the expected usage of such a (costly) solution.

Table 4. Online written exams in academic year 2020-21

\begin{tabular}{lccccc}
\hline Scenario & $\begin{array}{c}\text { \# of } \\
\text { sessions }\end{array}$ & $\begin{array}{c}\text { \% of } \\
\text { sessions }\end{array}$ & $\begin{array}{c}\text { Average \# of students } \\
\text { per session }\end{array}$ & $\begin{array}{c}\text { \# of examined } \\
\text { students }\end{array}$ & $\begin{array}{c}\text { \% of examined } \\
\text { students }\end{array}$ \\
\hline Exam.net & $7 \cdot 630$ & $80.8 \%$ & 21.2 & $161 \cdot 598$ & $66.9 \%$ \\
Moodle with SEB & $1 \cdot 190$ & $12.6 \%$ & 27.6 & $32 \cdot 883$ & $13.6 \%$ \\
Moodle without SEB & 184 & $1.9 \%$ & 19.3 & 3.542 & $1.5 \%$ \\
Proctoring & 436 & $4.6 \%$ & 99.8 & $43 \cdot 498$ & $18.0 \%$ \\
\hline Total & $\mathbf{9 * 4 4 0}$ & $\mathbf{1 0 0 . 0 \%}$ & $\mathbf{2 5 . 6}$ & $\mathbf{2 4 1 \cdot 5 2 1}$ & $\mathbf{1 0 0 . 0 \%}$ \\
\hline
\end{tabular}

\section{ANALYSIS OF STUDENT GRADES}

After one year of application of the techniques described above for carrying on written exams, it seemed interesting to look at the grades given to students. To this purpose, it necessary to know that:

- grades in Italian Universities are given in thirtieths;

- the minimum grade for passing an exam (thus for being registered in the University database) is 18 thirtieths;

- besides 30 thirtieths, it is possible to obtain a "30 cum laude" grade, corresponding by convention to 33 thirtieths. 
ONLINE WRITTEN EXAMS AT THE UNIVERSITY OF MILAN DURING COVID-19 CRISIS

On the basis of the above, we compared grades obtained by our students in academic years 2018-19 vs. 2020-21. Results are given in Tables 5 and 6.

Table 5. Comparison of grades in 2018-19 vs. 2020-21 by session month

\begin{tabular}{lccccc}
\hline Scenario & $\begin{array}{c}\text { Exam sessions } \\
\mathbf{2 0 1 8 - 1 9}\end{array}$ & $\begin{array}{c}\text { Average grade } \\
\text { in } \mathbf{2 0 1 8 - 1 9}\end{array}$ & $\begin{array}{c}\text { Exam sessions } \\
\mathbf{2 0 2 0 - 2 1}\end{array}$ & $\begin{array}{c}\text { Average grade } \\
\text { in 2020-21 }\end{array}$ & $\begin{array}{c}\text { Delta grade } \\
\mathbf{2 0 2 0 - 2 1}-\mathbf{2 0 1 8 - 1 9}\end{array}$ \\
\hline May & 1.102 & 24,67 & 1.032 & 25,31 & $\mathbf{0 , 6 4}$ \\
June & 2.477 & 25,54 & 1.923 & 25,76 & $\mathbf{0 , 2 2}$ \\
July & 3.197 & 24,99 & 2.518 & 25,38 & $\mathbf{0 , 3 9}$ \\
September & 3.043 & 24,46 & 2.556 & 24,96 & $\mathbf{0 , 5 0}$ \\
October & 497 & 24,05 & 428 & 24,84 & $\mathbf{0 , 7 9}$ \\
November & 896 & 24,18 & 702 & 23,66 & $\mathbf{- 0 , 5 2}$ \\
December & 827 & 25,66 & 680 & 26,13 & $\mathbf{0 , 4 7}$ \\
January & 2.116 & 25,31 & 1.729 & 25,66 & $\mathbf{0 , 3 6}$ \\
February & 2.868 & 25,44 & 2.500 & 25,44 & $\mathbf{- 0 , 0 1}$ \\
March & 471 & 25,26 & 502 & 25,73 & $\mathbf{0 , 4 7}$ \\
April & 838 & 25,18 & 767 & 24,88 & $\mathbf{- 0 , 3 0}$ \\
\hline Total & $\mathbf{1 8 . 3 3 2}$ & $\mathbf{2 5 , 1 7}$ & $\mathbf{1 5 . 3 3 7}$ & $\mathbf{2 5 , 4 1}$ & $\mathbf{0 , 2 4}$ \\
\hline
\end{tabular}

Table 6. Comparison of grades in 2018-19 vs. 2020-21 by faculty

\begin{tabular}{lccc}
\hline Scenario & $\begin{array}{c}\text { Average } \\
\text { grade }\end{array}$ & $\begin{array}{c}\text { Average } \\
\text { grade }\end{array}$ & $\begin{array}{c}\text { Delta grade } \\
\mathbf{2 0 2 0 - 2 1}- \\
\mathbf{2 0 1 8 - 1 9}\end{array}$ \\
\hline Agricultural and Food Sciences & $\mathbf{2 0 1 8 - 1 9}$ & in 2020-21 & $\mathbf{0 , 0 7}$ \\
Exercise and Sport Sciences & 24,42 & 24,49 & $\mathbf{0 , 0 5}$ \\
Humanities & 26,02 & 26,08 & $\mathbf{0 , 2 0}$ \\
Language Mediation and Intercultural Communication & 25,20 & 25,39 & $\mathbf{0 , 2 7}$ \\
Law & 25,24 & 25,50 & $\mathbf{- 0 , 1 2}$ \\
Medicine & 25,60 & 25,48 & $\mathbf{0 , 2 2}$ \\
Pharmacy & 25,83 & 26,05 & $\mathbf{0 , 3 1}$ \\
Political, Economic and Social Sciences & 24,34 & 24,64 & $\mathbf{0 , 4 9}$ \\
Science and Technology & 24,87 & 25,37 & $\mathbf{0 , 1 4}$ \\
Veterinary Medicine & 25,26 & 25,40 & $\mathbf{0 , 3 4}$ \\
\hline Total & 24,89 & 25,23 & $\mathbf{0 , 2 4}$ \\
\hline
\end{tabular}

From Tables 5 and 6 , it is possible to make the following considerations:

- grades during pandemic are almost always higher than before: perhaps, proctoring was not always a guarantee of correct behavior of the students, and/or teachers were less severe due to pandemic...

- however, the differences in grades are very seldom greater than half a thirtieth, and this happens in two months (May and October) not belonging to the breaks between lecture times, thus less significant from a statistical point of view;

- looking at the behavior of the faculties over the full academic year, the situation is even better: differences are always less than one third of thirtieth, with the only exception of the Political, Economic and Social Sciences faculty, increasing grades by almost half a thirtieth;

- the lower number of exam sessions in 2020-21 with respect to 2018-19 does not mean necessarily less students/exams: some teachers may have decided to transform written exams in oral form for a simpler management, especially when the number of students was low. 


\section{CONCLUSION}

After careful evaluation (and interaction with other Italian Universities facing similar problems) three different scenarios have been identified for carrying on written exams online during the Covid-19 emergency period. Cost and setup complexity of exam sessions using commercial proctoring platforms forced to limit this last scenario to very large groups of students $(\geq 100)$ to be evaluated in parallel: of course, this limitation has been considered excessive by some teachers, reluctant to perform by themselves a direct monitoring.

However, the identification of two scenarios allowing reasonably affordable handling of groups of $20 \div 30$ students by a single teacher or collaborator allowed the implementation of a lot of written exams, definitely less time consuming than the oral exams initially proposed as the only possible solution.

Results after the pandemic are encouraging: like Wibowo et al. (2016), we are definitely satisfied about the online management of written exams: numbers of handled students are not dramatically lower with respect to the normal situation before pandemic, and final grades given to students during pandemic result just a little higher than before.

As a final conclusion, we can state that we will adopt online written exams for particular situations (as, e.g., exams for full time employed students) even after pandemic.

\section{ACKNOWLEDGEMENT}

We would like to thank sincerely Dr. Tiziano Traversi, of the ICT Division of our University, for his invaluable support in extracting all the data necessary to perform the evaluations discussed so far.

\section{REFERENCES}

Ardid, M, Gómez-Tejedor, JA, Meseguer-Dueñas, JM, Riera, J \& Vidaurre, A 2014, 'Online exams for blended assessment. Study of different application methodologies', Computers and Education, vol. 81, pp. 296-303.

Exam.net 2020, A robust, easy-to-use and secure exam platform, viewed June $10^{\text {th }} 2020$, $<$ https://exam.net/>.

Haus, G, Pasquinelli, YB, Scaccia, D \& Scarabottolo, N 2020, 'Online Written Exams during Covid-19 Crisis', Proceeding of the Intl. Conf. e-Learning 2020, pp. 79-86.

Haus, G, Pasquinelli, YB, Scaccia, D \& Scarabottolo, N 2021, 'Online Written Exams during Covid-19 Crisis: an Update after One Year', Proceeding of the Intl. Conf. e-Learning 2021, pp. 115-119.

Hillier, M \& Fluck, A 2013, 'Arguing again for e-exams in high stakes examinations', 30th ascilite Conference 2013 Proceedings, pp. 385-396.

Proctorio 2020, A Comprehensive Learning Integrity Platform, viewed June $10^{\text {th }} 2020$, < https://web.proctorio.com/>.

Respondus 2020, Assessment Tools for Learning Systems, viewed June $10^{\text {th }} 2020$, $<$ https://web.respondus.com/>.

SEB 2020, Safe Exam Browser, viewed June 10 $0^{\text {th }} 2020$, < https://safeexambrowser.org/>. 
ONLINE WRITTEN EXAMS AT THE UNIVERSITY OF MILAN DURING COVID-19 CRISIS

Troussas, C, Krouska, A \& Sgouropoulou, C, 'Collaboration and fuzzy-modeled personalization for mobile game-based learning in higher education', Computers \& Education, Volume 144, 2020.

Troussas, C, Krouska, A \& Sgouropoulou, C, 'A Novel Teaching Strategy Through Adaptive Learning Activities for Computer Programming', IEEE Transactions on Education, vol. 64, no. 2, pp. 103-109, May 2021.

Truszkowski, D 2019, 'Proctored Versus Non-Proctored Testing: A Study for Online Classes', Dissertation of the Doctoral Program of the American College of Education.

Weiner, JA \& Hurtz, GM 2017, 'A Comparative Study of Online Remote Proctored versus Onsite Proctored High-Stakes Exams', Journal of Applied Testing Technology, vol. 18, no. 1, pp. 13-20.

Wibowo, S, Grandhi, S, Chugh, R \& Sawir, E 2016, 'A Pilot Study of an Electronic Exam System at an Australian University', Journal of Educational Technology Systems, Vol 45, Issue 1, 2016.

Xiao, C \& Li, Y, 'Analysis on the Influence of the Epidemic on the Education in China', 2020 International Conference on Big Data and Informatization Education (ICBDIE), 2020, pp. 143-147. 